\title{
APAKAH DANA ZAKAT DAPAT MENGURANGI TINGKAT KEMISKINAN ?: STUDI KASUS PROVINSI SUMATRA BARAT
}

\author{
Yunila Dwi Putri ${ }^{1}$, Rayna Kartika ${ }^{2}$, \& Riyadi Aprayuda ${ }^{3}$ \\ ${ }^{1,2}$ Fakultas Ekonomi, Universitas Andalas \\ ${ }^{3}$ Fakultas Ekonomi dan Bisnis, Universitas Muhammadiyah Riau \\ Email : yunila152@gmail.com
}

\begin{abstract}
ABSTRAK
Penelitian ini bertujuan untuk menganalisis pengaruh jumlah dana zakat yang disalurkan ke masyarakat dan pertumbuhan ekonomi terhadap tingkat kemiskinan. Sampel penelitian ini adalah 18 BAZNAS kabupaten/kota di Sumatera Barat dengan data selama 6 tahun periode (2013-2019) dengan 126 jumlah pengamatan. Metode analisis penelitian ini regresi berganda. Hasil penelitian menunjukkan bahwa dana zakat dan pertumbuhan ekonomi memiliki dampak negatif signifikan terhadap tingkat kemiskinan. Penelitian ini memberikan prespektif bahwa peran dana zakat yang distribusikan kepada masyarakat mampu menunjukkan konsistensinya dan berhasil mengurangi tingkat kemiskinan sehingga dana zakat mampu menjadi strategi utama untuk mengurangi tingkat kemiskinan. Sebagai kontribusi praktis, pemerintah dapat lebih mengoptimalkan sosialisasi kepada masyarakat untuk menyalurkan dana zakat kepada lembaga berbadan hukum seperti BAZNAS, karena lebih terukur dalam melihat dampaknya terhadap perekonomian makro secara kesuluruhan untuk suatu daerah kabupaten/kota, agar tercapai pengentasan kemiskinan dari penyaluran dana zakat.
\end{abstract}

Kata kunci : Dana Zakat, Pertumbuhan Ekonomi, Kemiskinan.

\begin{abstract}
This study aims to analyze the effect of the amount of zakat funds distributed to the community and economic growth on poverty levels. The sample of this research was 18 BAZNAS districts/cities in West Sumatra with data for 6 years period (2013-2019) with 126 total observations. The method of analysis of this research is multiple regression. The results showed that zakat funds and economic growth have a significant negative impact on poverty levels. This study provides a perspective that the role of zakat funds distributed to the community can show consistency and succeed in reducing poverty levels so that zakat funds can become the main strategy for reducing poverty levels. As a practical contribution, the government can further optimize the socialization to the community to distribute zakat funds to legal entities such as BAZNAS, because it is more measurable in seeing its impact on the macroeconomy as a whole for a district/city, to achieve poverty alleviation from the distribution of zakat funds.
\end{abstract}

Keywords : Zakat Fund, Economic Growth, Poverty. 


\section{PENDAHULUAN}

Kemiskinan telah menjadi masalah ekonomi, sosial, dan politik di seluruh dunia terutama di negara-negara berkembang dan termasuk banyak negara muslim (Nadzri, Rahman, \& Ormar, 2014). Sebagai negara berkembang, jumlah orang yang berada dibawah garis kemiskinan masih menjadi masalah utama (Ayuniyyah et al., 2018). Oleh karena itu, masalah kemiskinan harus segera diatasi agar tidak menjadi berdampak besar dalam perekonomian suatu negara (Muthalib et al., 2018). Ayuniyyah et al., (2018) menyebutkan penangulangan kemiskinan pantas mendapat prioritas dalam strategi pembangunan ekonomi nasional (Ayuniyyah et al., 2018). Salah satu strategi untuk menyelesaikan kemiskinan adalah dengan menggunakan instrumen yang didasarkan pada budaya atau agama lokal (Ishaq, 2003). Indonesia merupakan penduduk yang mayoritasnya beragama Islam, menurut BPS 87,2\% penduduk Indonesia memeluk agama Islam. Oleh sebab itu, karena zakat merupakan kewajiban bagi yang beragama Islam maka potensi zakat bisa menjadi roda penggerak perekonomian untuk membantu kesejahteraan. Dalam hal ini, lembaga zakat dengan pemberdayaan kegiatan zakat dianggap sebagai salah satu mekanisme yang paling efektif untuk menangani masalah kemiskinan (Pramanik, 1993). Pendapat ini sejalan dengan temuan Ayuniyyah et al., (2018), dan Johari, Aziz, \& Ali (2014). Hasil peneltian mereka mengungkapkan bahwa zakat dapat mengurangi tingkat kemiskinan. Secara spesifik, Beik (2014) menjabarkan bahwa kehadiran program zakat mampu menurunkan jumlah kemiskinan sebesar 10,79 persen, hasil penelitian mereka menunjukkan konsistensi dan keberhasilan dalam program distribusi zakat. Kemudian, Faiz (1991) menjabarkan bahwa zakat telah memberi manfaat 7,21 juta atau 42,58 persen dari total rumah tangga miskin di Pakistan pada tahun 1988. Selanjutnya, Abdullah et al., (2015) menemukan bukti bahwa efektivitas zakat terbukti merupakan suatu cara yang sangat efektif dalam membantu orang miskin, membebaskan mereka dari parahnya kemiskinan, sehingga pengumpulan dana zakat harus menjadi prioritas.

Badan Amil Zakat Nasional (Baznas) salah satu lembaga yang berwenang memberdayakan dana zakat di Indonesia untuk membantu mensejahterakan para mustahik sehingga meningkatkan taraf kehidupan mereka menjadi lebih baik. Bersamaan dengan itu, sebagai salah satu provinsi yang memiliki nilai kultur Islami terdapat peningkatan penerimaan dana zakat setiap tahun pada Provinsi Sumatra Barat seperti ditunjukkan pada tabel 1 .

Tabel 1. Penerimaan Dana Zakat 2013-2018

\begin{tabular}{cr}
\hline Tahun & Total Penerimaan Dana Zakat \\
\hline 2013 & Rp. $5.698 .039 .385,00$ \\
2014 & Rp. $6.787 .766 .928,00$ \\
2015 & Rp. $7.463 .013 .735,00$ \\
2016 & Rp. $11.149 .385 .130,00$ \\
2017 & Rp. $8.519 .815 .809,00$ \\
2018 & Rp. 12.815 .438 .981
\end{tabular}

Sumber : Baznas Provinsi Sumatra Barat (2020) 
Berdasarkan data tabel 1 jumlah dana penerimaan sangat besar dan meningkat setiap tahun, walaupun terjadi penurunan pada tahun 2017, namun pada tahun 2018 kembali mengalami peningkatan yang signifikan dari tahun- tahun sebelumnya. Namun demikian, hal ini tidak sejalan dengan jumlah penduduk miskin yang berada pada Provinsi Sumatra Barat, jumlah penduduk miskin masih menunjukkan fluktuasi seperti yang ditunjukkan pada Grafik 1.

\section{Grafik 1. Jumlah Penduduk Miskin Provinsi Sumatra Barat (Dalam Ribuan)}

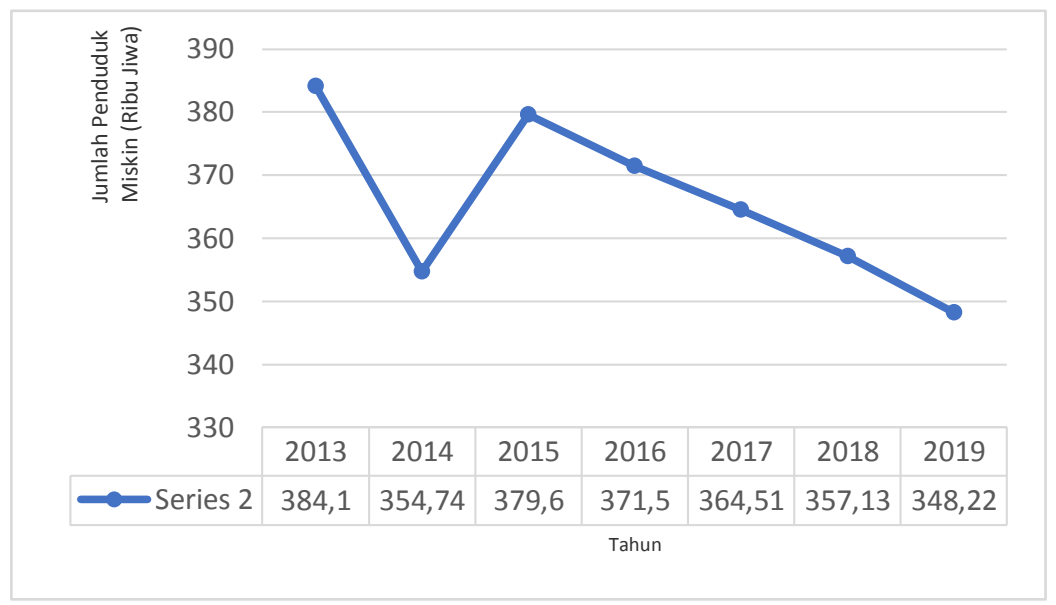

Sumber : BPS Provinsi Sumatra Barat (2020)

Grafik 1 menunjukkan bahwa jumlah penduduk yang berada dibawah garis kemiskinan mengalami penurunan tajam pada tahun 2013 ke tahun 2014, dan kembali meningkat tajam pada tahun 2015 dan perlahan menurun hingga di tahun 2019. Hal ini menunjukkan masih terdapat fluktuasi jumlah masyarakat yang berada dibawah garis kemiskinan. Oleh sebab itu, peran dari retribusi dana zakat ikut serta menekan angka kemiskinan dan mensejahterakan mustahik penting untuk diselidiki lebih lanjut, terutama dalam penurunan kemiskinan di empat tahun terakhir sesuai fluktuasi grafik ditingkat penduduk miskin (2014-2019).

Selain zakat, peran variabel makro ekonomi seperti pertumbuhan ekonomi juga berperan mengurangi dampak kemiskinan. Abdullah, Derus, \& AlMalkawi (2015) menyebutkan faktor utama yang memainkan peran penting dalam mengurangi kemiskinan dan ketimpangan adalah pertumbuhan ekonomi. Hal ini dibuktikan pada penelitian Benerjee, Banik \&
Mukhopadyay, (2015), dan Datt, Ravallion \& Murgai (2016) yang mengungkapkan bahwa terdapat penurunan besar dalam tingkat kemiskinan kemungkinan disebabkan oleh peningkatan pertumbuhan ekonomi. Selanjutnya Stevans \& Sessions (2005) menemukan bukti bahwa ada korelasi negatif yang kuat antara pertumbuhan ekonomi dan kemiskinan yang diperkirakan akan bertahan di masa depan. Secara khusus, mereka mengungkapkan bahwa pertumbuhan ekonomi berperan penting di India setelah reformasi 1990an untuk mengurangi kemiskinan. Kemudian, Choudhury \& Harahap (2008) mengungkapkan bahwa Produk Domestik Bruto (PDB) merupakan hal penting untuk memunculkan pentingnya zakat dalam proses pembangunan ekonomi, sehingga zakat dan PDB adalah instrumen yang saling berhubungan.

Penelitian sebelumnya telah melakukan penelitian terkait hubungan zakat terhadap kemiskinan di Indonesia pada provinsi Banda Aceh (Muliadi \& 
Amri, 2019; Amri \& Marwiyati 2019; Afifudin \& Sari, 2019). Sepengetahuan peneliti, peneliti belum menemukan penelitian yang mengindentifikasi peran distribusi dana zakat mengurangi tingkat kesmiskinan di Sumatera Barat yang dimana mayoritas penduduknya rata-rata juga beragama islam, dan suku di Sumatra Barat adalah Minang Kabau yang memiliki budaya yang memahami aturan budaya dan agama yaitu adat yang bersendikan syariat yang dikenal dengan istilah "Adat Basandi Syara', Syara' Basandi Kitabullah. Oleh sebab itu, penelitian ini ingin mengetahui tentang dana retribusi zakat agar tepat sasaran serta bisa bermanfaat dalam waktu jangka panjang bagi para mustahik. Secara khusus, tujuan penelitian ini adalah. Pertama, menguji secara empiris Dana zakat terhadap tingkat kemiskinan. Kedua, menguji secara empiris pertumbuhan ekonomi terhadap tingkat kemiskinan. Hasil penelitian ini menemukan bahwa dana zakat dan pertumbuhan ekonomi berhasil mengurangi tingkat kemiskinan di Sumatera Barat. Sebagai kontribusi praktis, pemerintah dapat lebih mengoptimalkan sosialisasi kepada masyarakat untuk menyalurkan dana zakat kepada lembaga berbadan hukum seperti BAZNAS, karena lebih terukur dalam melihat dampaknya terhadap perekonomian makro secara kesuluruhan untuk suatu daerah kabupaten/kota, agar tercapai pengentasan kemiskinan dari penyaluran dana zakat.

\section{TINJAUAN PUSTAKA}

\section{Zakat dan Kemiskinan}

Eksistensi zakat dalam meningkatkan taraf hidup masyarakat miskin menjadi bagian penting dari ajaran Islam (Johari et al., 2014). Strategi Islam dalam Al-Qur'an, memperhatikan masalah sosial dan pengentasan kemiskinan, berupa mengajak atau memberi makan fakir miskin dan dengan memberikan sebagian rezeki, memberikan hak-hak kepada orang miskin dan sedang terlantar dalam perjalanan, membayar zakat, infak, sedekah dan perbuatan baik lainnya, sehingga Islam bersikap sangat perduli kepada nasib orang miskin yang terlantar (Qardhawi, 1995). Kata "al-zakah" telah disebutkan tiga puluh kali dalam Alquran. Secara harafiah, zakat berarti untuk tumbuh dan meningkat, sementara secara syariah, zakat adalah konsep yang merujuk pada redistribusi kekayaan yang ditentukan oleh Allah SWT ke dalam kategori orang yang layak menerimanya. Selain tingkat kemiskinan, zakat bertujuan untuk menghilangkan kerakusan di kalangan umat muslim dan mendorong perilaku yang berorientasi sosial. Secara keseluruhan, diharapkan pembayaran zakat akan memurnikan pendapatan dari pembayar zakat, mendamaikan hati pembayar dan asnaf, memenuhi kebutuhan dasar orang miskin dan yang membutuhkan, dan menyelesaikan masalah sosial seperti kemiskinan, pengangguran, hutang dan distribusi pendapatan yang tidak adil (Dogarawa, 2009; Al-Qaradawi, 1999). Menurut Mahamod (2012), sistem seperti zakat juga ada dalam agama lain seperti konsep Hindu tentang pemberian sedekah (dikenal sebagai datrtadatrtva); dana pada Buddhisme; dan tithe dalam agama Kristen. tithe misalnya mengacu pada persyaratan membayar sebagian dari pendapatan seseorang kepada Gereja untuk pemeliharaan institusi, dukungan para menterinya, promosi pekerjaannya dan bantuan bagi orang miskin.

Penelitian mengenai dampak zakat terhadap kemiskinan telah menjadi perhatian banyak peneliti. Sebagian di antara mereka membuktikan signifikansi dan eksistensi dana zakat dalam menurunkan tingkat kemiskinan (Abdelbaki,2013., Aisyah, 2014., Murniati \& Beik, 2015., Muliadi \& Amri, 2019., Amri, 2019., Afifudin \& Sari, 2019). Di 
sisi lain terdapat hasil kajian empiris yang menyimpulkan bahwa zakat memiliki kontribusi relatif kecil terhadap penurunan kemiskinan (Ali et al., 2015). Kemudian, zakat dapat meningkatkan pendapatan dan memperbaiki kondisi ekonomi penerima zakat, tetapi tidak secara signifikan terdampak pada pengurangan jumlah penduduk miskin (Hoque et al., 2015; Redha et al., 2016). Namun, sejumlah peneliti menemukan bahwa dana zakat tidak mampu memperbaiki kesejahteraan kelompok miskin. Indeks kemiskinan masyarakat tidak mengalami perubahan antara kondisi sebelum dan setelah menerima zakat (Beik \& Tsabita, 2017). Penyaluran dana zakat kepada kelompok miskin tidak mampu mengurangi jumlah penduduk miskin secara aggregate (Nurjanah et al., 2019). Secara umum zakat belum berdampak signifikan terhadap perbaikan kesejahteraan masyarakat (Khasandy \& Badrudin, 2019). Dalam nada yang sama, Soekarni et al., (2008) menunjukan bahwa secara umum zakat belum mampu mengurangi jumlah orang miskin secara signifikan. Tingkat keberhasilan lembaga-lembaga pengelola zakat, terutama BAZIS DKI Jakarta, BAZDA Banjarnegara, BAZ Pekasiran dan LAZIS Baitul Makmur Kepakisan, baru sampai pada tingkat mengurangi beban hidup orang miskin, yang oleh program penyaluran zakat lebih banyak diarahkan untuk hal-hal yang bersifat konsumtif dan nilai bantuan yang diberikan juga relatif kecil karena dana yang terkumpul masih terbatas, sedangkan jumlah orang yang dibantu sangat banyak.

Temuan sejumlah peneliti di atas secara eksplisit menginformasikan bahwa dampak zakat terhadap penurunan kemiskinan masih perlu menjadi perdebatan, karena pendistribusian dana zakat kepada kelompok miskin dapat meningkatkan pendapatan dan memperbaiki konsumsi mereka, namun penggunaan dana zakat tersebut belum sepenuhnya mampu menyelesaikan persoalan kemiskinan secara umum

\section{Pertumbuhan Ekonomi dan Kemiskinan}

Istilah pertumbuhan ekonomi menerangkan atau mengukur prestasi dan perkembangan suatu perekonomian. Pertumbuhan ekonomi dapat juga diartikan sebagai kenaikan Gross domestic product (GDP) atau Gross National Product (GNP) tanpa memandang apakah kenaikan itu lebih besar atau lebih kecil dari tingkat pertumbuhan penduduk, atau apakah perubahan struktur ekonomi terjadi atau tidak (Arsyad 1999). Strategi pertumbuhan dapat mempengaruhi kesejahteraan masyarakat melalui pertumbuhan dan efek tingkatnya seiring dengan berjalannya waktu (Chani et al., 2011). Kesejahteraan dari kebijakan publik ini dapat muncul dalam berbagai bentuk seperti menurunkan subsidi dan pembayaran transfer lainnya oleh pemerintah kepada masyarakat yang terpinggirkan (Chani et al., 2011). Hal ini dapat menyebabkan penurunan pendapatan siap pakai serta meningkatkan kecenderungan mereka untuk mengkonsumsi. Menurut teori pertumbuhan endogen, simpanan yang rendah secara negatif mempengaruhi pertumbuhan output (Agenor et al., 2000) Pemotongan investasi oleh pemerintah (terutama di infrastruktur) menurunkan investasi swasta di negara tersebut yang mengakibatkan pertumbuhan ekonomi yang rendah.

Loayza (1996) menyimpulkan bahwa meningkatkan pendapatan pemerintah melalui peningkatan tarif pajak menghambat investasi swasta di negara tersebut. Hal ini menyebabkan penurunan pertumbuhan ekonomi dan penurunan pendapatan pemerintah dalam jangka panjang. Hal ini membatasi kapasitas pemerintah untuk berinvestasi di 
sektor sosial dan pembangunan, yang pada akhirnya meningkatkan kemiskinan. Choi et al., (1996) menemukan bahwa pertumbuhan ekonomi suatu negara dikaitkan dengan inflasi dan penyesuaian ekonomi makro. Proses penyesuaian mengurangi ketidakstabilan makroekonomi dan meningkatkan pertumbuhan ekonomi, sementara inflasi menghantam orang miskin lebih parah daripada orang kaya dan berpenghasilan tinggi. Kemudian, Bruno \& Easterly (1998) dan Sarel (1996) menemukan bahwa kebijakan stabilisasi untuk mengendalikan inflasi menguntungkan kelas miskin daripada kaya. Banyak sekali faktor yang menyebabkan tingginya angka kemiskinan. Selanjutnya, Gylfason (1998) menyimpulkan bahwa inflasi yang rendah dan pertumbuhan ekonomi yang tinggi meningkatkan alokasi sumber daya yang efisien, meningkatkan lapangan kerja, meningkatkan investasi dan dengan demikian mengurangi kemiskinan.

Dollar (2007) menyelidiki faktorfaktor yang dapat mengurangi kemiskinan. Dia menemukan bukti bahwa konsensus tentang peran penting yang dimainkan oleh pertumbuhan ekonomi dalam mengurangi kemiskinan. Namun, beberapa penelitian seperti Chani \& Chaudhary (2010), dan Bourguignon (2006) menegaskan bahwa pertumbuhan ekonomi yang inklusif berperan untuk pengentasan kemiskinan. Secara umum hasil empiris menekankan bahwa hanya pertumbuhan dengan pemerataan dapat mengurangi kemiskinan.

\section{METODE PENELITIAN}

Unit analisis penelitian ini adalah Badan Amil Zakat Nasional (BAZNAS). Populasi adalah BAZNAS yang ada di seluruh kabupaten/Kota di Sumatera
Barat. Periode penelitian adalah untuk data selama 8 tahun (2013-2019) yang melibatkan 18 BAZNAS kabupaten/kota di Sumatera Barat dan data dari Badan Pusat Statistik dengan jumlah pengamatan 72. Secara khusus, kajian ini untuk melihat pengaruh jumlah dana zakat dan pertumbuhan ekonomi Sumatera Barat terhadap tingkat penduduk miskin. Tingkat kemiskinan yang diteliti pada penelitian ini adalah persentase jumlah penduduk miskin yang memiliki rata-rata pengeluaran perkapita perbulan dibawah garis kemiskinan. Kemudian, pertumbuhan ekonomi yang diteliti mengunakan indikator PDB atas dasar harga berlaku yaitu nilai tambah barang dan jasa dihitung menggunakan harga yang berlaku setiap tahun. Data dianalisis menggunakan analisis regresi berganda dengan menggunakan uji asumsi klasik berupa uji normalitas, uji multikolinieritas, uji heteroskedastisitas, dan uji autokorelasi serta menguji hipotesis menggunakan uji secara parsial $(\mathrm{t})$, simultan $(\mathrm{F})$ dan koefisien determinasi $\left(\mathrm{R}^{2}\right)$. Persamaan regresi data panel adalah sebagai berikut:

\section{$\mathrm{Y} 1=\mathrm{a}+\mathrm{b} 1$ Dana ZISit + b2 PDBit +eit}

\section{HASIL DAN PEMBAHASAN}

Untuk memenuhi asumsi multivariat normality, dilakukan uji normalitas. Uji normalitas digunakan untuk menguji data terdistribusi normal atau tidak. Dalam penelitian ini pengujian dilakukan menggunakan statistik OneSample Kolmogorov-Smirnovi Test, dengan melihat nilai dari Asymp. Sig. Apabila data tersebut memiliki nilai sig > alpha $(\alpha=0,05)$, maka data dikatakan berdistribusi normal (Ghozali, 2017). Hasil uji normalitas dapat dilihat pada tabel 2 berikut ini. 
Tabel 2. Hasil Uji Normalitas

\begin{tabular}{cc}
\hline & $\begin{array}{c}\text { Unstandardized } \\
\text { Residual }\end{array}$ \\
\hline $\mathrm{N}$ & 126 \\
Kolmogorov-Smirnov Z & .594 \\
Asymp Sig. (2-tailed) & .873 \\
\hline
\end{tabular}

Sumber : Data diolah (2020)

Sebagaimana dilihat pada tabel 2 dilakukan uji asumsi klasik. Pertama, nilai asymp. sig. (2-tailed) bernilai 0.873. dilakukan uji multikoliearitas untuk Hal ini menunjukkan bahwa nilai tersebut menguji ada atau tidaknya korelasi dalam lebih besar dari $5 \%(0.873>0.05)$ model regresi dengan melihat nilai sehingga dapat dinyatakan data penelitian tolerance dan Variance Inflation Factor terdistribusi secara normal. Selanjutnya, (VIF). Uji Multikoleniaritas dapat dilihat karena asumsi multivariat normality telah berdasarkan nilai VIF dan nilai tolerance. terpenuhi sebelum mamasuki uji regresi Hasil uji dapat dilihat dari tabel 3.

Tabel 3. Hasil Uji Multikolinearitas

\begin{tabular}{ccc}
\hline Model & \multicolumn{2}{c}{ Collinearity Statistics } \\
\cline { 2 - 3 } & Tolerance & VIF \\
\hline Dana Zakat & .999 & 1.001 \\
PDB & .999 & 1.001 \\
\hline
\end{tabular}

Sumber : Data diolah (2020)

Tabel 3 menunjukkan hasil Tolerance (.999) dan Varience Inflatuon Factor (VIF) (1.001) dimasing-masing variabel dana zakat dan PDB. Ghozali (2017) menyebutkan bahwa jika nilai tolerance kecil dari 0.10 dan VIF besar dari 10, maka terdapat masalah multikoliniaritas. Berdasarkan hasil pengujian nilai tolerance tidak lebih kecil dari pada $0.10(.999>0.10)$ dan nilai VIF tidak lebih dari $10(1.001<10)$ untuk kedua variabel independen dana zakat dan PDB, sehingga tidak terdapat masalah multikoleniaritas antara variabel independen dalam model regresi. Kedua, untuk uji heteroskedastisitas peneliti menggunakan uji glejser yaitu dengan cara meregresikan antara variabel independen dengan nilai absolute residualnya (Ghozali, 2017). Jika nilai signifikansi antara variabel independen dengan absolute residual lebih dari 0,05 maka dapat disimpulkan bahwa tidak terjadi heteroskedastisistas (Ghozali, 2017). Hasil uji heteroskedastisitas dapat dilihat pada tabel 4 .

\section{Tabel 4. Hasil Uji Heteroskedastisitas}

\begin{tabular}{ll}
\hline \multicolumn{1}{c}{ Model } & Sig \\
\hline (Constant) & .143 \\
Dana Zakat & .928 \\
PDB & .493 \\
\hline
\end{tabular}

Sumber : Data diolah (2020)

Tabel 4 diperoleh nilai korelasi menggunakan unstandardized residual masing-masing variabel dengan dan nilai absolute residual pada variabel 
terikat (abs_res) memiliki nilai signifikansi lebih dari $0.05(>0.05)$ ini berarti bahwa semua variabel terbebas dari masalah heteroskedastisitas pada model regresi. Terakhir, untuk model regresi yang baik biasanya tidak terjadi masalah
Untuk membuktikan model regresi terbebas dari autokorelasi yaitu dengan melihat nilai Durbin-Watson (DW), nilai DW yang diperoleh harus lebih besar dari DU dan lebih kecil dari 4-DU (DU < DW < 4-DU) (Ghozali, 2017). Hasil uji autokorelasi dapat dilihat pada tabel 5 .

Tabel 5. Hasil Uji Autokorelasi

\begin{tabular}{cc}
\hline & Model Summary $^{b}$ \\
\hline Model & Durbin-Watson \\
\hline 1 & 2,543 \\
\hline
\end{tabular}

Sumber : Data diolah (2020)

Berdasarkan pengujian yang dapat dilanjutkan. Hasil Regresi Linear dilakukan sebelumnya penelitian ini berganda pada penelitian ini dapat dilihat terbebas dari masalah asumsi klasik. Oleh pada tabel 6 .

sebab itu, pengujian regresi berganda

Tabel 6. Hasil Analisis Regresi Berganda

\begin{tabular}{cccccc}
\hline Model & \multicolumn{2}{c}{ Unstandardized Coefficients } & $\begin{array}{c}\text { Standardized } \\
\text { Coefficients }\end{array}$ & \multirow{2}{*}{ t } & Sig. \\
\cline { 2 - 4 } & $\mathbf{B}$ & Std. Error & Beta & & \\
\hline (Constant) & .389 & .064 & & 6.123 & .000 \\
Dana Zakat & -.004 & .002 & -.235 & -2.755 & .007 \\
PDB & -.025 & .009 & -.229 & -2.679 & .008 \\
\hline
\end{tabular}

Sumber : Data diolah (2020)

Tabel 6 menyajikan hasil uji regresi linier berganda dana ZIS dan pertumbuhan ekonomi, terhadap tingkat kemiskinan. Hasil estimasi dari model statistik menunjukkan pengaruh signifikan dari dana ZIS dan petumbuhan ekonomi pada tingkat kemiskinan. Tabel 6 diperoleh nilai konstanta (a) adalah .389 artinya jika dana zakat dan pertumbuhan ekonomi nilainya adalah 0 maka tingkat kemiskinan nilainya positif, yaitu .389. Koefisien regresi variabel dana zakat $\left(b_{1}\right)$ bernilai negatif, yaitu -.004 maka setiap peningkatan dana zakat sebesar 1, maka tingkat kemiskinan penghasilan akan menurun sebesar -.004 dengan asumsi bahwa variabel bebas lainnya bernilai konstan. Pertumbuhan ekonomi $\left(\mathrm{b}_{2}\right)$ bernilai negatif yaitu -.025 maka setiap peningkatan penagihan pajak sebesar 1 , tingkat kemiskinan akan menurun sebesar -.025 dengan asumsi bahwa variabel bebas lainnya bernilai konstan. Kemudian, Hasil Uji F untuk pengujian variabel secara bersama-sama dapat dilihat pada tabel 7 . 
Tabel 7. Hasil Uji F

\begin{tabular}{lccccc}
\hline \multicolumn{1}{c}{ Model } & Sum of Squares & df & Mean Square & F & Sig. \\
\hline Regression & .127 & 2 & .064 & & \\
Residual & 1.093 & 123 & .009 & 7.154 & .001 \\
Total & 1.221 & 125 & .064 & & \\
\hline
\end{tabular}

Sumber : Data diolah (2020)

Tabel 7 memiliki nilai Signifikansi sama berpengaruh terhadap tingkat .001 , artinya Sig < 0.05. Oleh sebab itu, kemiskinan. Selanjutnya, Hasil koefisien dapat disimpulkan bahwa dana zakat dan determinasi dapat dilihat pada Tabel 8 .

pertumbuhan ekonomi secara bersama-

Tabel 8. Hasil Koefisien Determinasi

\begin{tabular}{ccccc}
\hline Model & R & R Square & $\begin{array}{c}\text { Adjusted } \\
\text { R Square }\end{array}$ & $\begin{array}{c}\text { Std. Error of } \\
\text { the Estimate }\end{array}$ \\
\hline 1 & $.323^{\mathrm{a}}$ & .104 & .090 & .094285 \\
\hline
\end{tabular}

Sumber : Data diolah (2020)

Tabel 8 diatas menunjukkan nilai $\mathrm{R}$ Square yang telah disesuaikan (Adjusted $R$ Square) sebesar 0.090 ini berarti sumbangan pengaruh variabel independen terhadap variabel dependen sebesar 9\%, sedangkan sisanya dipengaruhi oleh variabel lain yang tidak dimasukkan dalam model ini.

Hasil uji dana ZIS memiliki pengaruh negatif, tabel 7 Menunjukkan signifikansi variabel dana zakat menunujukkan nilai lebih kecil dari taraf nyata $(0.007<0.05)$ artinya dana zakat secara parsial berpengaruh signifikan terhadap tingkat kemiskinan. Selajutnya, koefisien variabel inflasi sebesar -.004 menunjukkan bahwa dana zakat dengan tingkat kemiskinan memiliki hubungan negatif, yang dimana dana zakat berpengaruh mengurangi tingkat kemiskinan. Hasil ini menunjukkan bahwa dana ZIS yang disalurkan kepada masyarakat dapat mengurangi tingkat kemiskinan (Beik, 2013). Zakat merupakan mekanisme paling efektif untuk menangani permasalahan kemiskinan serta membantu orang miskin untuk membebaskan mereka dari kemiskinan (Ahmad, 1991., Pramanik, 1993., Abdullah, Derus \& Al-malkawi,
2015., Ayuniyyah et al., 2018). Distribusi dana ZIS oleh lembaga Baznas kepada masyarakat telah menunjukkan konsistensinya, sehingga berhasil mengurangi tingkat kemiskinan di Sumatera Barat yang dan berperan dalam penurunan penduduk miskin beberapa tahun terakhir. Hasil penelitian ini mengkonfirmasi penelitian Johari, Aziz, \& Ali (2014) yang menyatakan bahwa distribusi zakat telah membuktikan keefektifannya dalam meningkatkan pendapatan bulanan dan harian per individu untuk penerima zakat. Selanjutnya, temuan penelitian ini mengindikasi semakin tinggi dana zakat yang didistribusikan akan mengurangi tingkat kemiskinan dan ketimpangan, kondisi ini didukung oleh kesadaran masyarakat Sumatera Barat untuk memenuhi kewajiban membayar zakat seperti yang di perintahkan oleh agama Islam, maka ini menunjukkan bahwa umat muslim di Sumatera Barat memiliki nilainilai agama (religiusitas) yang kuat atau lebih tinggi jadi sangat mungkin untuk mematuhi kewajiban membayar zakat sehingga penyaluran dana zakat memiliki potensi yang cukup untuk mengurangi tingkat kemiskinan. Hasil penelitian ini 
mendukung temuan Abdelbaki (2013), Aisyah (2014), Afifudin \& Sari, (2019), Murniati \& Beik (2015), Muliadi \& Amri (2019), dan Amri (2019) yang menumukan bukti dana zakat berpengaruh dalam mengurangi tingkat kemiskinan.

Hasil uji pertumbuhan ekononomi memiliki pengaruh negatif, tabel 6 menunjukkan signifikansi variabel pertumbuhan ekonomi menunujukkan nilai lebih kecil dari taraf nyata $(0.008<$ 0.05) artinya pertumbuhan ekonomi secara parsial berpengaruh signifikan terhadap tingkat kemiskinan. Kemudian, koefisien variabel inflasi sebesar -.025 menunjukkan bahwa pertumbuhan ekonomi dengan tingkat kemiskinan memiliki hubungan negatif, yang dimana pertumbuhan ekonomi berpengaruh mengurangi tingkat kemiskinan. Hasil ini menunjukkan kenaikan pertumbuhan ekonomi akan berdampak pada penurunan tingkat kemiskinan. Hal ini sejalan dengan beberapa penelitian terdahulu Stevans \& Sessions (2005) Banerjee et al (2015)., Datt et al. (2016)., Nakabashi (2018). Mereka menemukan bahwa penurunan besar dalam tingkat kemiskinan disebabkan oleh peningkatan pertumbuhan ekonomi. Kemudian, temuan penelitian ini sejalan dengan penelitian Stevans \& Sessions, (2005) yang menemukan bukti bahwa terdapat korelasi negatif antara pertumbuhan ekonomi dan kemiskinan. Selanjutnya, hasil penelitian ini mengkonfirmasi temuan Devangi \& Lee (2013) yang menyatakan pertumbuhan ekonomi sebagai salah satu faktor utama dibalik pengurangan kemiskinan. Penelitian ini juga mengindikasi semakin tinggi pertumbuhan ekonomi akan mengurangi tingkat kemiskinan di Sumatera Barat. Pertumbuhan ekonomi yang lebih tinggi akan mengurangi peningkatan tingkat kemiskinan untuk semua masyarakat (Stevans \& Sessions, 2005).

\section{KESIMPULAN}

Distribusi dana dana zakat yang disalurkan kepada masyarakat terbukti mengurangi tingkat kemiskinan. Ini berarti, penyaluran dana oleh lembaga Baznas kepada masyarakat telah menunjukkan konsistensinya sehingga berhasil mengurangi tingkat kemiskinan di Sumatera Barat. Zakat memiliki potensi untuk mengurangi kemiskinan di Sumatera Barat. Kondisi ini didukung oleh kesadaran masyarakat Sumatera Barat yang memiliki penduduk mayoritas muslim yang mematuhi kewajiban membayar zakat. Oleh sebab itu, semakin tinggi jadi semakin tinggi dana zakat yang didistribusikan akan semakin mengurangi tingkat kemiskinan. Hal ini sejalan dengan masyarakat Minang Kabau yang memiliki budaya yang memahami aturan budaya dan agama yaitu adat yang bersendikan syariat yang dikenal dengan istilah "Adat Basandi Syara', Syara' Basandi Kitabullah". Penelitian ini memberikan prespektif bahwa peran dana ZIS yang distribusikan kepada masyarakat mampu menjadi strategi utama untuk mengurangi tingkat kemiskinan. Pertumbuhan Ekonomi mampu secara langsung menjadi salah satu faktor utama untuk mengurangi tingkat kemiskinan. Karena ada korelasi negatif antara pertumbuhan ekonomi dan kemiskinan mengindikasi Semakin tinggi pertumbuhan ekonomi akan mengurangi tingkat kemiskinan di Sumatera Barat. Zakat memiliki dampak positif pada pembangunan ekonomi dan pertumbuhan ekonomi yang lebih tinggi akan mengurangi peningkatan tingkat kemiskinan diseluruh masyarakat. Penelitian ini memberikan kontribusi pada masukan untuk pemerintah yaitu lebih mengoptimalkan sosialisasi kepada masyarakat untuk menyalurkan dana zakat kepada lembaga berbadan hukum seperti BAZNAS, karena lebih terukur dalam melihat dampaknya terhadap perekonomian makro secara kesuluruhan 
untuk suatu daerah kabupaten/kota. Agar tercapai pengentasan kemiskinan dari penyaluran dana ZIS yang diberikan, maka BAZNAS dalam mengkalokasikan zakat dan menentukan mustahik harus sesuai dengan ketentuan yang termuat dalam Q.S. At-Taubah (9) ayat 60, bahwa zakat itu hanyalah diperuntukkan untuk orang-orang fakir, orang-orang miskin, pengurus-pengurus zakat, para mu'allaf, untuk memerdekakan budak, orang-orang yang berhutang, untuk jalan Allah SWT dan untuk mereka yang sedang dalam perjalanan sebagai suatu ketetapan yang diwajibkan Allah SWT, dan Allah SWT maha mengetahui lagi maha bijaksana. Keterbatasan penelitian ini, hanya melihat distribusi dana zakat secara keseluruhan saran untuk penelitian berikutnya lebih melihat lebih spesifik instrumen zakat infaq dan sedakah yang dimana masingmasing berperan terhadap tingkat kemiskinan, dan juga tingkat kemiskinan pada penelitian ini hanya secara general dari total persentase penduduk miskin yang diperoleh dari garis kemiskinan. Penelitian berikutnya lebih disarankan memilah lebih spesifik kelompok antara kemiskinan kronis dan kemiskinan sementara (misalnya, Mai \& Mahadevan, 2016).

\section{DAFTAR PUSTAKA}

Abdelbaki, H. H. 2013. The Impact of Zakat on Poverty and Income Inequality in Bahrain. Rev. Integr. Bus. Econ. Res, 2(1), 133-154.

Abdullah, N., Derus, A. M., \& AlMalkawi, H.A. N. 2015. The Effectiveness of Zakat in Alleviating Poverty and Inequalities. Humanomics, 31(3), 314-329.

Afifudin, T., \& Sari, N. 2019. Pengaruh Zakat dan Infaq terhadap Penurunan Kemiskinan di Aceh Periode 20072017. Jurnal Ekonomi dan Bisnis Islam, 4(1), 34-51.
Agénor, P. R., McDermott, C. J., \& Prasad, E. S. 2000. Macroeconomic Fluctuations In Developing Countries: Some Stylized Facts. The World Bank Economic Review, 14(2), 251-285.

Ahmad, Z. 1991. Islam, Poverty And Income Distribution. The Islamic Foundation, Markfield Da'wah Center. Leicester.

Aisyah, M. 2014. The Role of Zakah and Binary Economics in Poverty Reduction, ESENSI : Jurnal Bisnis dan Manajemen, 4(2),178-197.

Ali, A. F. M., Abd Rashid, Z., Johari, F., \& Ab Aziz, M. R. 2015. The Effectiveness olf Zakat In Reducing Poverty Incident: An Analysis in Kelantan, Malaysia. Asian Social Science, 11(21), 355.

Al-Qaraḍāwī, Y. 1999. Fiqh Az-zakat: A Comparative Study; The Rules, Regulations and Philosophy of Zakat in the Light of the Qur'an and Sunna. Dar Al Taqwa.

Amri, K., \& Marwiyati, M. 2019. Preferensi Muzakki Membayar Zakat Melalui Baitul Mal: Studi Empiris di Kota Banda Aceh. $J$ MAS (Jurnal Manajemen dan Sains), 4(2), 386-391.

Arsyad, L. 1999. Pengantar Perencanaan Dan Pembangunan Ekonomi Daerah. Badan Penerbitan Fakultas Ekonomi (BPFE). Yogyakarta.

Ayuniyyah, Q., Pramanik, A. H., Saad, N. M., \& Ariffin, M. I. 2018. Zakat For Poverty Alleviation And Income Inequality Reduction: West Java, Indonesia. Journal of Islamic Monetary Economics and Finance, 4(1), 85-100.

Banerjee, A. N., Banik, N., \& Mukhopadhyay, J. P. 2015. The Dynamics of Income Growth And 
Poverty: Evidence From Districts in India. Development Policy Review, 33(3), 293-312.

Beik, I. S. 2014. Towardss an Establishment of an Efficient and Sound Zakat System: Proposed Core Principles for Effective Zakat Supervision. Paper presented in the Working Group of Zakat Core Principles 2014.

Beik, I. S., \& Tsabita, K. 2017. Performance Analysis of Zakat Practices in East Lampung Regency using National Zakat Index (NZI). Working Papers-Puskas Baznas, 1 .

Bourguignon, F., \& Spadaro, A. 2006. Microsimulation As A Tool For Evaluating Redistribution Policies. The Journal of Economic Inequality, 4(1), 77-106.

Bruno, M., \& Easterly, W. 1998. Inflation Crises And Long-Run Growth, Journal of Monetary Economics, 41, 3-26.

Chani, D., Irfan, M., Pervaiz, Z., Jan, S. A., Ali, A., \& Chaudhary, A. R. 2011. Poverty, Inflation And Economic Growth: Empirical Evidence From Pakistan. World Applied Sciences Journal, 14(7), 1058-1063.

Chani, M. I., \& Chaudhary, A. R. 2010. Import Demand Behaviour in Pakistan: An Empirical Analysis. LAP LAMBERT Academic Publishing. Germany.

Choi, E. S., Hokom, M. M., Chen, J. L., Skrine, J., Faust, J., Nichol, J., \& Hunt, P. 1996. The Role Of Megakaryocyte Growth And Development Factor In Terminal Stages Of Thrombopoiesis. British journal of haematology, 95(2), 337233.
Choudhury, M. A., \& Harahap, S. S. 2008. Interrelationship Between Zakat, Islamic Bank And The Economy. Managerial Finance, 34(9), 610-617.

Datt, G., Ravallion, M., \& Murgai, R. 2016. Growth, Urbanization, And Poverty Reduction in India. The World Bank.

Devangi, H., Liyanage \& Lee, P. G. H. 2013. Have Economic Growth and Institutional Quality Contributed to Poverty and In-equality Reduction in Asia?. Journal of A-sian Economics, 6, 1-33.

Dogarawa, A. B. 2009. Poverty Alleviaton Through Zakah And Waqf Institutions: A Case For The Muslim Ummah In Ghana. Available at SSRN 1622122.

Dollar, D. 2007. Poverty, Inequality, And Social Disparities During China's Economic Reform. The World Bank.

Faiz, M. 1991. Prospects Of Poverty Eradication Through The Existing Zakat System In Pakistan. Pakistan Development Review, 30(4), 11191129.

Ghozali, I. 2017. Aplikasi Analisis Multivariate Dengan Program IBM SPSS 23. [Multivariate Analysis Application With The IBM SPSS 23 program]. Badan Penerbit Universitas Diponegoro. Semarang.

Gylfason, T. 1998. Output Gains From Economic Stabilization. Journal of Development Economics, 56(1), 8196.

Hoque, N., Khan, M. A., \& Mohammad, K. D. 2015. Poverty Alleviation by Zakah in a Transitional Economy: A Small Business Entrepreneurial Framework. Journal of Global Entrepreneurship Research, 5(1), 120. 
Ishaq, K. A. 2003. Integrating Traditional Institutions in International Development: Revitalizing Zakat to Reduce Poverty in Muslim Societies. University of Oregon.

Johari, F., Ab Aziz, M. R., \& Ali, A. F. M. 2014. The Role Of Zakat In Reducing Poverty And Income Inequality Among New Convert (Muallaf) in Selangor, Malaysia. Online Journal of Research in Islamic Studies, 1(3), 43-56.

Khasandy, E. A., \& Badrudin, R. 2019. The Influence of Zakat on Economic Growth And Welfare Society In Indonesia. Integrated Journal of Business and Economics, 3(1), 6579.

Loayza, N. 1999. The Economics Of The Informal Sector: A Simple Model And Some Empirical Evidence from Latin America. The World Bank.

Mahamod, L. H. 2012. The Alleviation Of Rural Poverty in Malaysia: The Role Of Zakat A Case Study. Journal of Architecture, Planning and Construction Management, 2(1), 93.

Mai, T., \& Mahadevan, R. 2016. A Research Note on The Poverty Dynamics and Cost Of Poverty Inequality: Case Study of Indonesia. Economic Analysis and Policy, 49, 100-107.

Muliadi, M., \& Amri, K. 2019. Penerimaan Zakat dan Penurunan Kemiskinan di Aceh: Peran Dana Otonomi Khusus Sebagai Pemoderasi. Jurnal Ilmiah Ekonomi Islam, 5(3), 231-244.

Murniati, R., \& Beik, I. S. 2015. Pengaruh Zakat Terhadap Indeks Pembangunan Manusia Dan Tingkat Kemiskinan Mustahik: Studi Kasus Pendayagunaan BAZNAS Kota Bogor. Jurnal Al-Muzara'ah, 2(2),
135-149.

Muthalib, A. A., Adam, P., Saenong, Z., \& Suriadi, L. O. 2018. The Influence of Fuel Prices and Unemployment Rate towards the Poverty Level in Indonesia. International Journal of Energy Economics and Policy, 8(3), 37-42.

Nadzri, F. A. A., Rahman, R., \& Ormar, N. 2014. Zakat and Poverty Alleviation: Roles of Zakat Institutions in Malaysia. International Journal of Arts and Commerce, 1(7), 61-72.

Nakabashi, L. 2018. Poverty And Economic Development: Evidence For The Brazilian States. EconomiA, 19(3), 445-458.

Nurjanah, F. 2019. The Impact of Economic Growth and Distribution of Zakat Funds on Poverty (Survey in the Third District of West Java Province Period 2011-2016). KnE Social Sciences, 55-70.

Pramanik, A. H. 1993. Development and Distribution in Islam. Pelanduk Publications. Petaling Jaya-Kuala Lumpur.

Qardhawi, Y. 1995. Kiat Islam Mengentaskan

Kemiskinan. Terjemahan. Gema Insani. Jakarta.

Rédha, B. M., Larbi, G., \& Karima, R. M. 2016. The Impact of Zakat Fund in Reducing Poverty Case of Algeria. Mediterranean Journal of Social Sciences, 7(3), 256.

Sarel, M. 1996. Nonlinear Effects Of Inflation On Economic Growth. Staff Papers, 43(1), 199215.

Soekarni, M. 2008. Investasi Syari'ah Implementasi Konsep pada Kenyataan Empiris. Kreasi Wacana. Yogyakarta. 
2020, Jurnal Tabarru' : Islamic Banking and Finance 3 (2) : 248 - 261

Stevans, L. K., \& Sessions, D. N. 2005. An Empirical Investigation Into The Effect of Music Downloading on The Consumer Expenditure of Recorded Music: A Time Series Approach. Journal of Consumer Policy, 28(3), 311-324. 